Gut, 1972, 13, 197-200

\title{
Effect of spironolactone on stool electrolyte losses during human cholera
}

\author{
RICHARD L. GUERRANT, LINCOLN C. CHEN, AND JON E. ROHDE \\ From the Pakistan-SEATO Cholera Research Laboratory, Dacca, East Pakistan
}

SUMMARY This study demonstrated that endogenous aldosterone, as determined by its transient competitive block by spironolactone, caused significant sodium and chloride retention during naturally acquired cholera. This beneficial effect of the hormone is accompanied, however, by a deleterious depletion of potassium. In addition, it was found that stool rate significantly altered the sodium and potassium concentrations in cholera stool despite minimal or absent aldosterone activity.

The ability of aldosterone to increase sodium absorption and potassium excretion in the distal tubule of the kidney (Laragh, 1967) is an important factor in the response to reduction in circulating vascular volume (Davis, Carpenter, Ayers, Holman, and Bahn, 1961). The action of pharmacological doses of aldosterone on electrolyte transport in colonic epithelium closely resembles its effect in the renal tubule (Shields, Mulholland, and Elmslie, 1966; Levitan and Goulston, 1967; Crocker and Munday, 1969).

The role of aldosterone has not been investigated during the volume-depleted state of acute cholera, and its influence on the electrolyte losses in the stool and the potassium depletion of cholera is unclear. This study explores the effect of aldosterone on stool electrolyte losses during cholera by employing spironolactone, a competitive antagonist of this hormone (Liddle, 1961; Porter, Bogoroch, and Edelman, 1964).

\section{Patients and Methods}

Twenty-three previously healthy adult male patients with bacteriologically confirmed cholera were selected for study. As stool rate is known to affect stool electrolyte composition (Watten, Blackwell, and Phillips, 1962), the patients were divided into two groups: one with constant stool rates during brisk diarrhoea, and the second group with declining stool rates during recovery from diarrhoea. All patients received intravenous therapy and standardized diets without salt restriction. The first

Received for publication 11 January 1972. group of 15 patients with constant stool rates was rehydrated but was maintained in a mildly hypovolaemic state with plasma specific gravities of 1.027 to 1.030 (normal $=1.024-1.027$ ) in order to retain the hypovolaemic stimulus to aldosterone release. During the course of study these patients demonstrated mild clinical dehydration with no sweat and low jugular venous pressure, but care was taken to prevent oliguria, postural hypotension, and tachycardia. Stool and urine were collected for eighthour periods and were analysed for sodium, potassium, chloride, and bicarbonate by standard methods. After two control periods a single oral dose of $100 \mathrm{mg}$ spironolactone (Aldactone-A, Searle and Co.) was given. Stool and urine collections were continued for an additional $\mathbf{4 8}$ hours.

A second group of eight patients with declining stool rates was studied. These patients were kept well hydrated (plasma specific gravities were 1.0221.026) with intravenous fluids to avoid any hypovolaemic stimulus to aldosterone release. In addition, they were given spironolactone $50 \mathrm{mg}$ orally every eight hours to block any remaining aldosterone effect. Stool and urine volume and electrolytes were determined for eight-hour periods until diarrhoea had stopped.

\section{Results}

As shown in Fig. 1, spironolactone significantly raised the sodium : potassium ratio of choleraic stool. This was effected both by an increase in sodium and a decrease in potassium concentrations, the latter being smaller and thus changing the ratio more. The effect of spironolactone began in most patients 


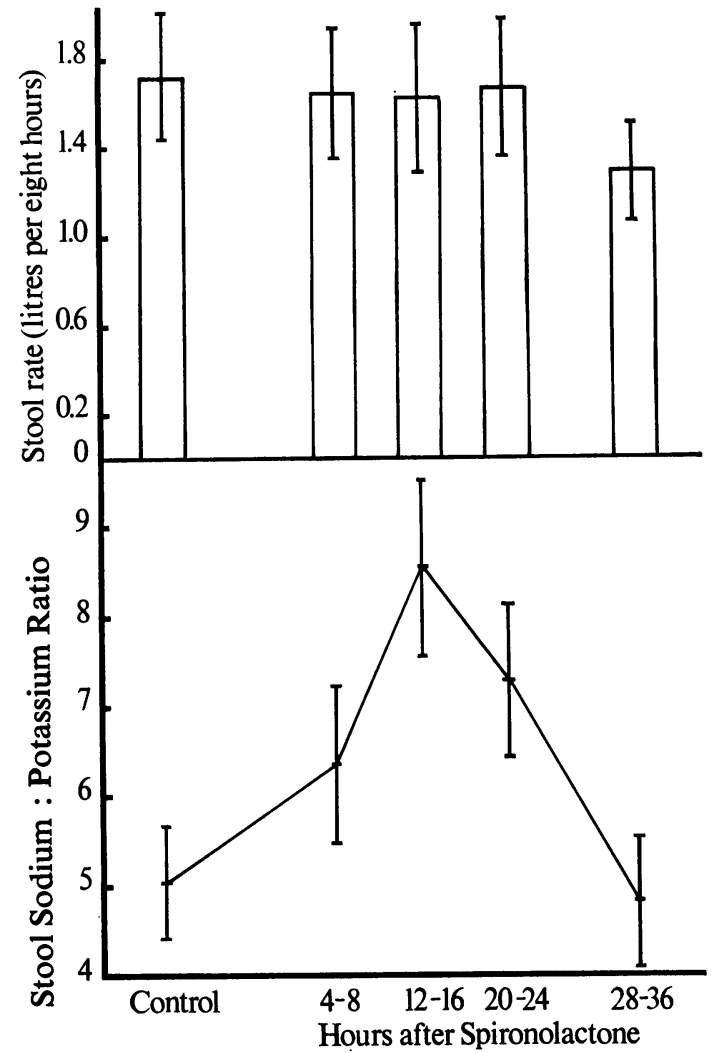

Fig. 1 Effect of spironolactone (100 mg) on average stool sodium: potassium ratios ( 1 I SEM) in 15 patients during cholera. Bar graph above shows there is no significant change of stool rate during the study period. Bottom graph shows average stool sodium: potassium ratios during 36 hours of study. Paired data show that the average rise in sodium:potassium ratio from control to peak (usually at 12-16 hours after spironolactone) is $4.63(\mathrm{P}<0.001)$, and fall from peak to control values (by 28-36 hours after spironolactone) is $4.89(\mathrm{P}<0.001)$. at four to eight hours with its peak effect at 12 to 16 hours. The average sodium : potassium ratio returned to the control value by 28 to 36 hours. Urinary sodium and potassium changes paralleled stool changes in both direction and time course. As seen at the top of Fig. 1, the average stool volume of each eight-hour period demonstrated that no significant change in stool rate occurred during the study period.

From the change in stool electrolyte composition between control periods and the peak effect of spironolactone, the retention of sodium and chloride and the loss of potassium due to the effect of aldosterone can be calculated (Table). The blocking action of spironolactone caused an additional daily loss of $74 \mathrm{~m}$-equiv of sodium and $35 \mathrm{~m}$-equiv of chloride as well as the retention of 71 m-equiv of potassium daily. Stool bicarbonate was not significantly influenced by spironolactone. Changes in urinary losses of sodium and potassium were smaller.

Figure 2 illustrates that as the stool rate declined in the second group of patients, the stool sodium : potassium ratio decreased, with both a decrease in sodium and an increase in potassium concentrations. Despite attempts at minimizing the influence of aldosterone by full hydration and administration of spironolactone, significantly lower sodium and greater potassium concentrations were present at slower stool rates.

\section{Discussion}

Aldosterone is known to play an important role in sodium and potassium metabolism (Yunis, Bercovitch, Stein, Levitt, and Goldstein, 1964; Gelb and Gerson, 1969). Spironolactone, because of its ability to compete with aldosterone at the target cell for a specific nuclear binding site, competitively antagonizes the action of aldosterone (Liddle, 1961; Porter

\begin{tabular}{|c|c|c|c|c|}
\hline & Control & $\begin{array}{l}\text { At Peak Spironolactone } \\
\text { Action }\end{array}$ & Net with Spironolactone & Significance \\
\hline $\begin{array}{l}\mathrm{Na} \\
\mathrm{K} \\
\mathrm{Cl} \\
\mathrm{HCO}\end{array}$ & $\begin{array}{r}526(110)^{2} \\
136(28 \cdot 6) \\
90(60 \cdot 8) \\
185(38.7)\end{array}$ & $\begin{array}{r}600(125) \\
65(13 \cdot 6) \\
325(68 \cdot 4) \\
215(45 \cdot 0)\end{array}$ & $\begin{array}{l}+74 \\
-71 \\
+35 \\
+30\end{array}$ & $\begin{array}{l}P<0.001 \\
P<0.001 \\
P<0.05 \\
\text { Not stated }\end{array}$ \\
\hline $\begin{array}{l}\text { Mean Ur } \\
\mathrm{Na} \\
\mathbf{K}\end{array}$ & $\begin{array}{l}e \text { Loss }^{3} \\
76(62) \\
44(36 \cdot 2)\end{array}$ & $\begin{array}{r}135(110) \\
30(24 \cdot 0)\end{array}$ & $\begin{array}{l}+59 \\
-14\end{array}$ & $\begin{array}{l}P<0.05 \\
P<0.05\end{array}$ \\
\hline
\end{tabular}

Table Mean stool loss (m-equiv per 24 hours) ${ }^{1}$

${ }^{2}$ Mean stool volume was 4.775 1 per 24 hours during study.

*Concentrations given in parentheses in $\mathrm{m}$-equiv per litre

'Mean urine volume was 1.230 1 per 24 hours during study. 


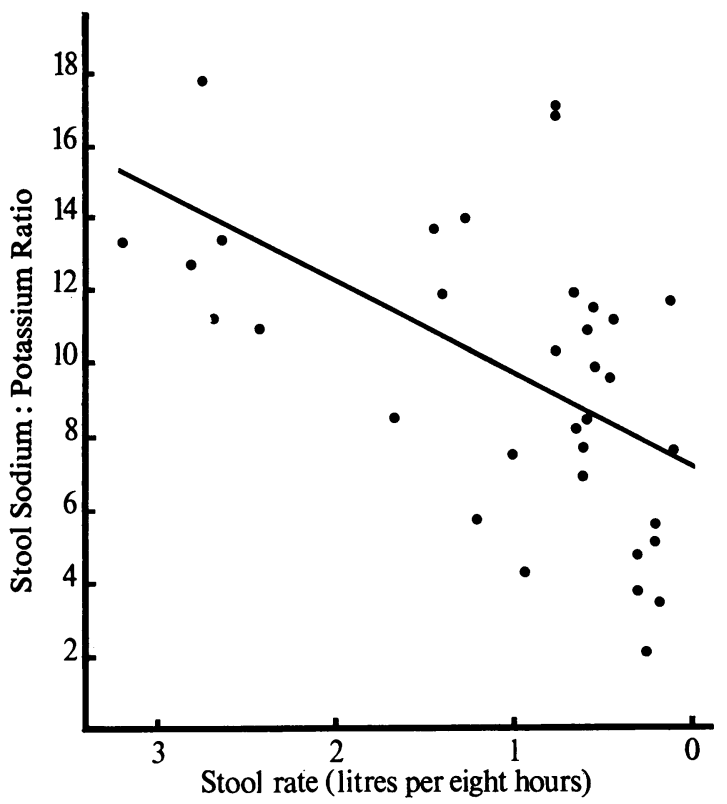

Fig. 2 Effect of spironolactone $(50 \mathrm{mg}$ every eight hours) on average stool sodium : potassium ratios during declining stool rates in eight well hydrated cholera patients. Correlation of stool rate with sodium: potassium ratios is highly significant $(\mathrm{P}<0.001$, $n=34)$. Regression equation with stool rate as the independent variable is $y=7 \cdot 168 \pm 2 \cdot 510 x ; r=0.5526$.

et al, 1964). This agent has been shown to block the increased entry of potassium into ileal and colonic loops of aldosterone-loaded dogs (Elmslie, Mulholland, and Shields, 1966).

During states of volume depletion, the increased secretion of aldosterotone leads to renal retention of sodium, a vital response to hypovolaemia (Davis et al, 1961). We have demonstrated that during the diarrhoea of cholera this hormone also leads to gastrointestinal retention of sodium and chloride and excretion of potassium. This is believed to occur predominantly in the colon. The electrolyte composition of choleraic small intestinal fluid has been shown to be similar to that of serum (Banwell, Pierce, Mitra, Brigham, Caranasos, Keimowitz, Fedson, Thomas, Gorbach, Sack, and Mondal, 1970). However, unless stool rate is extremely rapid, cholera stool contains decreased sodium and increased potassium concentrations, indicating significant sodium absorption and potassium excretion during transit through the colon (Watten $e t$ al, 1962; Banwell et al, 1970; Mahalanabis, Wallace, Kallen, Mondal, and Pierce, 1970). In our studies with uniform stool rates, spironolactone nearly doubled the stool sodium : potassium ratio. The beginning of the effect of spironolactone, the maximal effect, and the duration of effect on stool electrolytes are similar to those reported by Edmonds and Wilson (1960) on urine electrolytes.

From the data in Table it is clear that aldosterone, as determined from its transient block of spironolactone, caused retention of 74 m-equiv of sodium and $35 \mathrm{~m}$-equiv of chloride daily during cholera. However, this hormone simultaneously doubled gut potassium excretion and caused an additional daily stool potassium loss of $71 \mathrm{~m}$-equiv. This potentiates the dangerous potassium depletion in cholera. Although these effects are readily blocked by spironolactone, unfortunately potential renal effects in dehydrated patients preclude any recommendation for the use of this drug in cholera therapy.

During human cholera, a fall in stool sodium and rise in stool potassium concentrations have been reported as stool rate decreases, suggesting that cation transport is greater with slower transit time through the colon (Watten et al, 1962). Despite full hydration, which should minimize aldosterone secretion and specific inhibition of its action with spironolactone, we were unable to eliminate the fall in sodium concentration and rise in potassium concentration with declining stool rates. This suggests that with a prolonged colonic transit time transport of these cations may occur independently of aldosterone.

We thank Miss Dorothy Torrence and the nursing staff at PSCRL Hospital for their excellent care of patients being studied.

Reprint requests should be sent to Dr R. L. Guerrant, SEATO Cholera Research Programme, National Institute of Allergy and Infectious Diseases, Building 31, Room 7A03, National Institutes of Health, Bethesda, Maryland 20014, USA.

\section{References}

Banwell, J. G., Pierce, N. F., Mitra, R. C., Brigham, K. L., Caranasos, G. J., Keimowitz, R. I., Fedson, D. S., Thomas, J., Gorbach, S. L., Sack, R. B., and Mondal, A. (1970). Intestinal fluid and elec rolyte transport in human cholera. J. clin. Invest., 49, 183195.

Crocker, A. D., and Munday, K. A. (1969). Factors affecting mucosa water and sodium transfer in everted sacs of rat jejunum. $J$. Physiol. (Lond.), 202, 329-338.

Davis, J. O., Carpenter, C. C. J., Ayers, C. R., Holman, J. E., and Bahn, R. C. (1961). Evidence for secretion of an aldosteronestimulating hormone by the kidney. J. clin. Invest., 40, 684696.

Edmonds, C. J., and Wilson, G. M. (1960). The action of hydroflumethiazide in relation to adrenal steroids and potassium loss. Lancet, 1, 505-509.

Elmslie, R. G., Mulholland, A. T., and Shields, R. (1966). Blocking by spironolactone (SC 9420) of the action of aldosterone upon the intestinal transport of potassium, sodium and water. Gut, 7, 697-699. 
Gelb, A. M., and Gerson, C. D. (1969). Influence of the endocrine glands on small intestine absorption. Amer. J. clin. Nutr., 22, 305-310.

Laragh, J. H. (1967). Renin, angiotensin, aldosterone and hormonal regulation of arterial pressure and salt balance. Fed. Proc., 26, 39-41.

Levitan, R., and Goulston, K. (1967). Water and electrolyte content of human ileostomy fluid after d-aldosterone administration. Gastroenterology, 52, 510-512.

Levitan, R., and Ingelfinger, F. J. (1965). Effect of d-aldosterone on salt and water absorption from the intact human colon. J. clin. Invest., 44, 801-808.

Liddle, G. W. (1961). Specific and non-specific inhibition of mineralocorticoid activity. Metabolism, 10, 1021-1030.

Mahalanabis, D., Wallace, C. K., Kallen, R. J., Mondal, A., and Pierce, N. F. (1970). Water and electrolyte losses due to cholera in infants and small children: a recovery balance study. Pediatrics, 45, 374-385.
Porter, G. A., Bogoroch, R., and Edelman, I. S. (1964). On the mechanism of action of aldosterone on sodium transport: the role of RNA synthesis. Proc. nat. Aca. Sci. (Wash.), 52, 13261333.

Shields, R., Mulholland, A. T., and Elmslie, R. G. (1966). Action of aldosterone upon the intestinal transport of potassium, sodium, and water. Gut, 7, 686-696.

Watten, R. H., Blackwell, R. Q., and Phillips, R. A. (1962). The relation of electrolyte concentrations in plasma and excreta of cholera patients. In Papers Presented and Summaries of Discussions, SEATO Conference on Cholera, Dacca, 1960: pp 41-48. SEATO, Bangkok.

Yunis, S. L., Bercovitch, D. D., Stein, R. M., Levitt, M. F., and Goldstein, M. H. (1964). Renal tubular effects of hydrocortisone and aldosterone in normal hydropenic man: comment on sites of action. J. clin. Invest., 43, 1668-1676.

\section{The February 1972 Issue}

\section{THE FEBRUARY 1972 ISSUE CONTAINS THE FOLLOWING PAPERS}

${ }^{75}$ Se-selenomethionine scanning in the diagnosis of tumours of the pancreas and adjacent viscera: The use of the test and its impact on survival DENIS M. MCCARTHY, PAMELA BROWN, R. N. MELMED, J. E. AGNEW, AND I. A. D. BOUCHIER

The detection and measurement of circulating gastrin-like activity by bioassay D. G. COLIN-JONES AND J. E. LENNARD-JONES

Intestinal absorption of an arginine-containing peptide in cystinuria A. M. ASATOOR, B. D. W. HARRISON, M. D. MILNE, AND D. I. PROSSER

Effect of truncal vagotomy on acid and pepsin: Response to a cholinergic drug in man D. J. COWLEY

Intrajejunal volatile fatty acids in the stagnant loop syndrome A. J. CHERNOV, W. F. DOE, AND D.

Intraluminal fat digestion in the chronic alcoholic GARY M. ROGGIN, FRANK L. IBER, AND WILLEM G. LINSCHEER

Coeliac disease, vasculitis, and cryoglobulinaemia WILliam F. DOE, D. EVANS, J. R. HOBBS, AND C. C. BOOTH GOMPERTZ

Intraabdominal abscesses due to azathioprine for Crohn's disease T. C. NORTHFIELD AND C. I. ROBERTS

Plasma protein turnover (albumin, transferrin, IgG, IgM) in Ménétrier's disease (giant hypertrophic gastritis): Evidence of non-selective protein loss STIG JARNUM AND KURT BIRGER JENSEN

A clinical evaluation of ano-rectal pressure studies in the diagnosis of Hirschsprung's disease IAN AARONSON AND H. H. NIXON

Portal hypertension in kala-azar D. v. DATTA, $s$. SAHA, S. L. GROVER, SAMANT A. SINGH, R. N. CHAKRAVARTI, AND P. N. CHHUTTANI

\section{Technique}

New device for progressive dilatation of benign oesophageal stricture P. A. MAZURE, J. C. CHIOCCA, AND A. G. SFERCO

Progress report Hormonal control of pancreatic endocrine and exocrine secretion GILES YOUNGS

\section{Notes and activities}

Copies are still available and may be obtained from the PUBLISHING MANAGER,

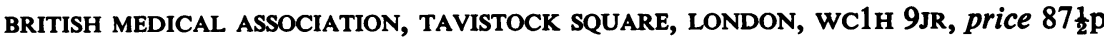

